stole. Prophylaxis in the absence of E.C.G. control may well produce unnecessary deaths.-I am, etc.,

Department of Medicine, St. Laurence's Hospital,

1 Horgan, J. H., Fournal of the Irish Medical Asso-
ciation, 1971, 64, 163.

J. H. HORGAN

\section{Suicide and Euthanasia}

SIR,- - I am concerned that the opinions of Dr. S. L. Henderson Smith (10 April, p. 111 and 5 June, p. 591) appear to be passing unopposed although I am encouraged by Dr. D. Hooker's letter (5 June, p. 585). With some re-wording, the latter could equally well apply to the euthanasia problem.

How can we accept the view that euthanasia would not be immoral? If Dr. Henderson Smith can define and authorize in this way, why should not Tom, Dick, and Harry also do so? Who has authority to decide what is moral and what is not? Which religion condones this taking of life and calls it moral?

Dr. Henderson Smith is rightly concerned about the problem of terminal suffering, although I feel his language is exaggerated, and his "daily ... appalling torture" is in sharp contrast with the view of your leading article (23 January, p. 187). The answer does not lie in euthanasia (in its curren meaning) but is a challenge to our profession to ease these sufferings, without "striving officiously to keep alive." With all the resources of modern medicine, combined with a real concern and compassion, we must be in a better position than ever to do this. This is not a question of confusion of semantics; whether we kill or whether we encourage or assist another to take his own life, this is immoral.

It has been my purpose in this letter to emphasize an underlying principle rather than the many practical problems such as uncertainty of prognosis and selection of patients, or the possible late results and abuses which would inevitably follow. We can now look back on the abortion law reform, and I sense that most of us do so with some regret. Are we going to stand by while vet another immoral and degrading Bill is slipped past us?

While I respect Dr. Henderson Smith's worthy intentions and concern about terminal suffering, I fear lest we may deviate from what is right by confused thinking.I am, etc.,

Bournemouth

D. A. ROCHE

Hants

\section{X-ray Equipment}

SIR,-At the meeting of the Radiologists' Group of the B.M.A. on 20 May one of the speakers put forward a suggestion of a panel of radiologists to advise the $x$-ray supply industry on the type of equipment required. One of the Department of Health medical advisory staff who was present promised to look into this and to consider setting up such a panel under the aegis of the Department.

The more I think about this proposal, the less I like it. It is obvious that the advice of such a panel would have to be available to all companies interested in supplying $x$-ray equipment. I wonder if the proposer of this panel had such a wide dissemination in mind? With the "benefit" of support from the Department, I fear that the advice of this panel would be regarded as binding. This could lead to over-standardization of equipment and to delays in introducing new ideas; few committees are sufficiently "light on their feet" for such a changing field as $x$-ray equipment.

For it to be at all effective the panel would have to be small and it would have to meet fairly frequently. Could such a panel be at all representative? The size and the facts of geography would be against it. Further, most $x$-ray apparatus is used by radiographers, not radiologists; giving them adequate representation would create further problems over committee size.

To sum up, I think such a panel would probably be too small to be truly representative, but too large to be effective. It would lead to centralization and standardization and thus have a stultifying effect on the design of $x$-ray equipment.

Far from centralization in this field I think we need to bring the decision making and financial responsibility down to local level Standardization has many benefits and we should try to evolve a system of purchasing $x$-ray equipment which encourages radiologists to buy standard equipment, but leaves latitude for purchase of modified or non-standard items where the local need demands it. I suggest that a hospital group should be allocated a number of "capital units" each year depending on the work done. Teaching and other special hospitals would have a loading factor depending on their particular requirements. Groups should be able to bank their units and earn interest or they could borrow on their "future earnings" and pay interest. Each year the Department should assess the cash value of a "capital unit." This calculation should be based on Hospital Equipment Note No. 6 . Diagnostic X-ray Department (H.M.S.O. 1962), a reasonable work load per room, and an average expectation of life of apparatus. The radiologists could then plan their purchase of $x$-ray equipment over a period of several years in the light of the needs of the group.

The mechanics of the system would be quite simple. The unit system is already in use in $x$-ray departments for assessing work load; 100 notional units might well equal one "capital unit." This $x$-ray unit system is now in need of updating and it requires some standardization of application, but would nevertheless be a practical basis of assessing work load. The figures are already returned at group, board, and Departmen levels, so that little work would be involved in allocating "capital units."

Such a system would put the decision making and the financial responsibility at the same level, that of the user of the equipment; this would fit in with modern ideas of management. It would give manufacturers the chance to plan their production; the inability to do such planning was one of the complaints made by the speaker mentioned in my first paragraph; he hoped his panel would, among other things, help him to do this forward planning.-I am, etc.,

Farnham Hospital,

D. J. MANTON

Farnham, Surrey
Logical Foundations of Medicine

SIR,-Like most general physicians I feel too out of my depth to engage in a technical argument with the computer experts. Nevertheless, because I feel that the medical man in the street must remain in contact with the computer men, I wish to discuss certain aspects of the paper by Professor W. I. Card and Professor I. J. Good (27 March, p. 718)

I concede that computers have a logic of their own, but surely it is a rigid logic compared with the flexibility of the logical processes of the human mind influenced by experience. The computer can adapt to changing situations but it must be programmed to adapt. The human mind is adapting as it goes along. Further, in relation to clinical facts, the computer only performs with information ascertained by clinicians, as distinct from its capacity to perform directly in relation to response to laboratory data. Skill in obtaining pertinent clinical facts is often what makes the difference between the good and the poor diagnostician. The computer can take a structured history, but can it take a good situational history, one in which skilled questioning flows from the subtleties of interpretive listening to patients' answers? There is an assumption that computer use is exclusively scientific. I suspect that a great deal of it is as much an art as is the practice of medicine.

The computer is one of many medical helps which are being promoted as ways of saving the doctor's time, and much of this development is legitimate and desirable. But we are saving the doctor's time for what purpose? Surely so that he can spend more of it in the business of clinical communication with the patient. A clinical history is not only an instrument of diagnosis, it is often an instrument of therapy. Talking to someone is more personal and satisfying than talking to something. Even if a computer takes a history, no doctor will believe it in his heart until he has checked at least some aspects of it with the patient, and no patient will believe he has been properly listened to unless he talks to a person.

How can a dermatologist use a computer? What rigmarole of documentation can supplant the instant view of a skin lesion? Who needs a computer to diagnose chicken pox and measles? The problems in acute alimentary bleeding have to do with detecting the bleeding lesion, with the techniques of investigation and not with the niceties of differential diagnosis. It does not need two hundred questions on a piece of paper to raise the suspicion of a duodenal ulcer. It needs five or six questions and clinical common sense. A computer can be encyclopaedic but it cannot be sensible. It can be systematic but not sensitive. The fact that common things commonly occur does not mean that the uncommon is not what my patient has. Unfortunately doctors do miss the diagnosis of myxoedema, but can myxoedematous patients fill in forms correctly?

Computers may have improved weather forecasting but they have not perfected it. Low pressure areas shift unexpectedly, other weather systems appear from nowhere. And there is only one weather forecast a day. How do you organize two or three million health forecasts a day? This must need a lot of time, energy, machinery, and people. And apart from the question whether clinical 
medicine can be computerized or not, do we want to computerize it? Sooner or later mankind must ask what it is going to do with all the human energy and time that the computers are beginning to release or make redundant. - I am, etc.,

W. C. WATSON

Department of Medicine and Gastrointestinal Unit, Victoria Hospital,

Ontario, Canada

\section{Child Health in a Changing Community}

SIR,-I read Professor S. D. M. Court's lecture with great interest (17 April, p. 125). It is indeed a masterly survey of the problem.

However, in his discussion of the partners in the team needed for a rising standard of child health he does not mention child health doctors in the clinical field employed by local authorities. Has he perhaps included them as paediatric specialists? With their knowledge of developmental paediatrics they are an important factor in seeing that the young handicapped child-from any cause-is able to fulfil his potential.-I am, etc.,

Muriel J. BRayshay President, Maternal and Child Health Group,
Society of Medical Officers of Health Manchester 23

\section{Health of Young People}

SIR,-Perhaps it is significant that in the same issue of the B.M.F. we have the stimulating article by Dr. Ronald Gibson "The Satchel and the Shining Morning Face" (5 June, p. 549) and the important letter by Dr. D. Hooker (5 June, p. 585) on abortions and legal and medical ethics. Could it be that at last the B.M.A. is becoming concerned about the behaviour of young people? There has always been interest in antenatal care, infant welfare, school health service, and care of young people at work. Can we at last turn our attentions to the effect on the health of young people by the increasing trivialization and commercialization of sex? If health education is to mean anything to the young it must provide the sort of information which can be understood. This must be scientific and strictly accurate. The recent report on the dangers of smoking is a good example.

The medical profession should be in the forefront of any campaign to raise the health of the nation. In the near future there will be an opportunity for those concerned about these problems to show their interest by action.-I am, etc.,

London N.W.6

STANLEy ElLison

\section{Failure to Continue Education}

SIR,-In an analysis ${ }^{1}$ of the response of 99 general practitioners to a programme of continuing education we found that 64 of them attended three or more local sessions during the 13 months of the study and 35 attended fewer than three. We thought we should try to find out how we could make our programme more attractive.

Thirty-four of the 35 are still in practice, and each was asked to complete a question- naire designed to find out what he thought about our postgraduate programme and what sort of meeting he would prefer. Thirty-two of the 34 did so. Those who had attended meetings elsewhere were asked their reasons for doing so, and what courses they had attended. Information about years since graduation and number in partnership was available for the 34 doctors (group 1) and for the 64 (group 2) who had attended three or more sessions.

The Figure shows the distribution of the 34 doctors in terms of years since graduation (hatched) set against that of the whole group. The figures in the hatched areas give the percentage of the total number of doctors in each column who attended fewer than three sessions. Sixteen $(47 \%)$ doctors in group 1 worked single-handed or in twoman practices compared with 20 (31\%) doctors in group 2, and $16(47 \%)$ in group 1 lived more than five miles $(8 \mathrm{~km})$ from the postgraduate centre compared with 23 $\left(36^{\circ} \%\right.$ ) in group 2 . The reason given for poor attendance by 15 was that the time was unsuitable. Most general practitioners living more than five miles $(8 \mathrm{~km})$ from the centre found lunch-time meetings difficult. Five stated that the subjects were sometimes irrelevant to general practice, and several commented that they were hospital orientated. Of the $18(56 \%)$ who attended approved meetings elsewhere 11 chose general subjects, five cardiology, four obstetrics, four psychiatry, three family planning, three management, and one each diabetes, forensic medicine, medical hypnosis, paediatrics, rheumatology, teaching, and the social aspects of general practice. Some said they attended meetings elsewhere to meet

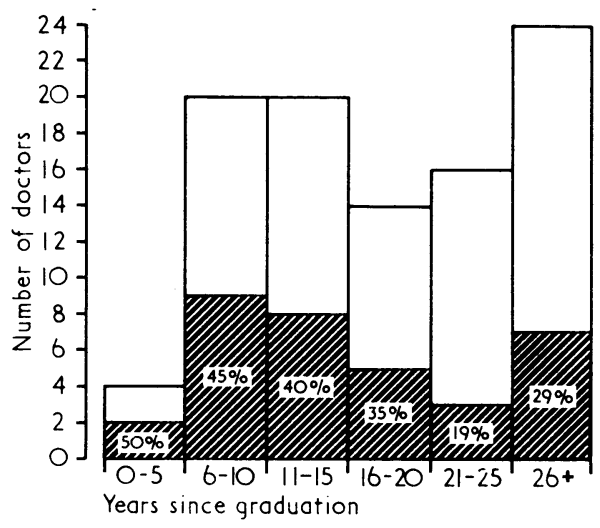

different people with different ideas. Seven held clinical posts in geriatrics, two in psychiatry, and one in anaesthetics. Of the 14 doctors in group 1 who did not attend meetings elsewhere eight ranked formal lectures first in their order of preference of type of meetings.

Contrary to our expectations the number of general practitioners attending more than three sessions increased with age, and this probably reflects the financial incentive inherent in seniority awards, which are payable only after 15 years. If meetings provide opportunities for learning it is no less important to offer incentives to recently qualified doctors, because it is easier to keep abreast of knowledge than to regain lost ground. Despite preference expressed for formal lectures we think they are of limited educational value. Meetings which encourage previous study and participation have been popular, ${ }^{1}$ and we are unwilling to change our policy. Some factors are beyond our control, but we shall try to encourage meetings at the periphery for those who find it difficult to come to our main centre and to promote as wide a variety of meetings as possible. We think incentives, financial or otherwise, might encourage younger doctors to attend. There will always be some who do not wish to come to meetings, but the onus is on the organizers to attract as many as possible.-We are, etc.,

J. T. CORBETT

P. G. DalgLeish

C. P. ElliotT-BinNS

T. A. RICHARDS E. D. SEVER

J. P. TOBY

Cripps Postgraduate Medical Centre,

Northampton

Sever, E. D., et al., British Medical fournal, 1971, 1 ,
164 .

\section{False Economy}

SIR,-I have received the current comparison of drug costs chart from the Department of Health and Social Security. It deals with hypnotics (ECL 106/69 Serial No. 4/71).

I accept that "It is not suggested that the above products necessarily have the same pharmacological properties." However, I also accept that five of the six products listed are the subject of ignorant or wanton abuse across the whole population spectrum and that such abuse is often of iatrogenic aetiology.

Unfortunately, the one compound which, so far, has not been implicated in this way is revealed as the most expensive.

In view of the current addiction problems I think that this chart-which implies and suggests preference for barbiturates-should have been withdrawn from the series. It will not alter my desire to wean my patients off the barbiturates or methaqualone, and possibly to substitute with nitrazepam. I hope that others will not find themselves feeling guilty at prescribing the safest hypnotic.-I am, etc.,

London N.9

Christopher J. DAY

\section{Coroner's Power to Commit for Trial}

SIR,-It is unfortunate that your legal correspondent, in discussing the coroner's power to commit for trial (26 June, p. 781), should misrepresent both the sequence of events which led to Ian Spencer's committal and also the meaning of my own remarks on this subject to which he refers. He clearly does not understand the normal procedure in these cases and has failed to appreciate the coroner's dilemma.

The position is as follows. If the Director of Public Prosecutions does not wish to proceed against a suspect in a case of homicide he writes to the police authority concerned to that effect and asks to be informed if any further evidence is revealed at the inquest. The case has then to be brought to inquest, and if it appears to the coroner that the death has been brought about by murder, manslaughter, or infanticide he is obliged to empanel a jury (Coroners' Amendment Act, 1926 Section 13 ss. 2). If after hearing the evidence the jury decide that there is a prima facie case of some form of homicide they must say so and if they feel that there is prima facie evidence 